\title{
(DES)ARTICULAÇÃO ENTRE CONHECIMENTOS MATEMÁTICOS E DIDÁTICOS-PEDAGÓGICOS: PERCEPÇÕES DE PROFESSORES EM INÍCIO DE DOCÊNCIA EM MATEMÁTICA
}

\author{
(DIS) ARTICULATION BETWEEN MATHEMATICAL AND DIDACTIC- \\ PEDAGOGICAL KNOWLEDGE: PERCEPTIONS OF TEACHERS IN THE \\ BEGINNING OF TEACHING IN MATHEMATICS
}

\author{
Rudinei dos Santos Lombardi \\ Universidade Federal do Rio Grande - FURG \\ lombardi.rdn@gmail.com \\ Fabrine Diniz Pereira \\ Universidade Federal do Rio Grande - FURG \\ fabrinediniz@,hotmail.com \\ Luana Maria Santos da Silva Ayres \\ Universidade Federal do Rio Grande - FURG \\ luana_ayres@,furg.br \\ Tanise Paula Novello \\ Universidade Federal do Rio Grande - FURG \\ tanisenovello@,furg.br
}

\begin{abstract}
Resumo
Inúmeras pesquisas buscam compreender o processo de formação inicial docente e essas têm apontado que os cursos de licenciatura ainda apresentam diversos desafios a serem superados. Nesse sentido, esta pesquisa buscou investigar a (des)articulação entre os conhecimentos matemáticos e didáticos-pedagógicos a partir da percepção de professores em início da docência em matemática. Para tanto, realizou-se entrevistas semiestruturadas com seis egressos do Curso de Licenciatura em Matemática da Universidade Federal do Rio Grande - FURG sobre as suas compreensões em relação a diversos aspectos referentes à sua formação inicial. Para analisar esses relatos utilizou-se o Discurso do Sujeito Coletivo (DSC) e emergiram três discursos: "Divergências entre Escola e Universidade"; "Desarticulação entre conhecimentos matemáticos e didáticospedagógicos"; e "Aproximação com o campo escolar". Nesse artigo será analisado o segundo discurso, através do qual foi possível perceber que para alcançar uma formação docente mais completa, não basta aproximar a Matemática acadêmica da Matemática escolar, também é preciso integrar o estudo dos conhecimentos didático-pedagógicos com o estudo dos conhecimentos matemáticos. Dessa forma, conclui-se que as disciplinas de conhecimentos específicos e didáticos são importantes para a constituição do docente, porém é importante que os cursos de formação inicial estabeleçam relações entre esses conhecimentos, superando as rupturas conceituais.

Palavras-chave: Formação Inicial; Licenciatura em Matemática; Egresso.
\end{abstract}




\begin{abstract}
Numerous researches seek to understand the process of initial teacher education and these have pointed out that undergraduate courses still present several challenges to be overcome. In this sense, this research sought to investigate the (dis) articulation between mathematical and didacticpedagogical knowledge from the perception of teachers in the beginning of teaching in mathematics. To this end, semi-structured interviews were conducted with six graduates of the Mathematics Degree Course at the Federal University of Rio Grande - FURG about their understandings in relation to several aspects related to their initial training. To analyze these reports, the Collective Subject Discourse (CSD) was used and three discourses emerged: "Divergences between School and University"; "Disarticulation between mathematical and didactic-pedagogical knowledge"; and "Approaching the school field". In this article, the second discourse will be analyzed, through which it was possible to realize that to achieve a more complete teacher education, it is not enough to bring academic mathematics and school mathematics together, it is also necessary to integrate the study of didactic-pedagogical knowledge with the study of mathematical knowledge. Thus, it is concluded that the disciplines of specific and didactic knowledge are important for the constitution of the teacher, however it is important that the initial training courses establish relationships between this knowledge, overcoming the conceptual ruptures.
\end{abstract}

Keywords: Initial formation; Degree in Mathematics; Egress.

\title{
INTRODUÇÃO
}

A sociedade está em constante transformação e por esse motivo surge a necessidade da escola estar em sincronia com os novos contextos e cenários que se apresentam como desafios à educação. Devido aos graves problemas que enfrentamos em relação ao processo de ensinar e aprender, a cada dia aumenta a preocupação com as licenciaturas, seja quanto às estruturas institucionais que as abrigam ou aos seus currículos e conteúdos formativos (GATTI, 2010). Deste modo, compreender como está acontecendo a formação inicial de professores de Matemática pode ser relevante para o planejamento de reformas curriculares e estruturais em cursos de licenciatura.

É comum se criticar o modelo de escola que se conhece, denominado por muitos como "tradicional", mas algumas licenciaturas também permanecem estruturadas nesse padrão tão criticado. Nesse sentido, Fiorentini (2005) afirma que as experiências vivenciadas no decorrer da formação inicial podem influenciar de forma significativa a sua prática docente no futuro. Desta forma, se torna contraditório esperar que sejam formados profissionais que valorizem a colaboração, a criatividade e a autonomia em sala de aula se ao longo de sua formação esses professores receberam uma educação no estilo “tradicional", na qual era mais fácil adotar posturas individualistas, lineares e passivas.

Nos Projetos Pedagógicos de Curso (PPC) das licenciaturas normalmente está previsto uma experiência acadêmica enriquecedora e que relacione os conhecimentos 
Lombardi, R. S.; Pereira, F. D.; Ayres, L. M. S. S.; Novello, T. P.

específicos estudados à vivência docente, mas na prática nem sempre se pode observar essa integração de conhecimentos. Segundo o artigo $5^{\circ}$, inciso IV, da Resolução CNE/CP 1, de 18 de fevereiro de 2002, Diretrizes Curriculares Nacionais para a Formação de Professores da Educação Básica, os PPC precisam considerar, além de outros fatores, que "os conteúdos a serem ensinados na escolaridade básica devem ser tratados de modo articulado com suas didáticas específicas". Nesse sentido, infere-se que, de maneira geral, os cursos de licenciatura não estão de acordo com essa resolução, pois ainda é marcante a ruptura entre disciplinas voltadas ao estudo teórico da área específica e disciplinas voltadas ao estudo de teorias da educação (núcleo comum das licenciaturas), sendo este último, muitas vezes, desvinculada do ensino de Matemática.

Para Gatti (2010) hoje temos um processo formativo com muitas 'emendas' e as rupturas são claras e evidentes. Para a autora, é necessário pensar a formação em currículos articulados, rompendo a lógica proeminente de organização a partir das ciências e seus diversos campos disciplinares; partindo para uma proposta que considere a função social própria à escolarização que é de "ensinar às novas gerações o conhecimento acumulado e consolidar valores e práticas coerentes com nossa vida civil” (GATTI, 2010, p. 1375). Assim, no que tange a formação de professores se faz necessário e urgente uma mudança nas estruturas das universidades, assim como nos currículos que compõe as licenciaturas.

Para que seja possível formar professores preparados para a realidade e adversidades das salas de aula não basta apenas que os cursos de licenciatura tenham um PPC estruturado dentro dos padrões exigidos a nível nacional. Nesse contexto, torna-se imprescindível existir coerência entre o que está previsto neste PPC e a realidade vivenciada pelos graduandos. Leal (2016) reforça que se faz necessário uma verdadeira articulação entre teoria e prática durante o processo formativo do futuro docente. Segundo a autora, é importante que os PPC das licenciaturas busquem contrapor a visão dicotômica no que diz respeito à relação entre teoria e prática buscando estabelecer uma relação de unidade entre elas.

Assim, teoria e prática, passam a serem compreendidas como componentes de uma atividade transformadora, de uma práxis. Leal (2016) destaca ainda que, em relação especificamente aos currículos dos cursos em Licenciatura em Matemática, é possível identificar uma visão dicotômica através da desvalorização das disciplinas de natureza pedagógico, nas quais teoricamente seria o espaço para a parte "prática" do curso, em 
contrapartida à valorização dos conhecimentos "específicos" da Matemática, desconsiderando as aplicações práticas e, o mais importante, sem considerar a forma como os licenciandos compreendem esses conhecimentos de modo a posteriormente vir a ensinálos.

Percebe-se também que mesmo nas disciplinas voltadas ao estudo dos conhecimentos matemáticos o futuro professor está construindo um saber pedagógico. Fiorentini (2005) aponta que, em muitos casos, esse aprendizado chega a influenciar mais a prática docente do que o concretizado nas disciplinas didático-pedagógicas, seja porque esse aprendizado geralmente reforça procedimentos vivenciados na etapa anterior de escolarização, seja porque o aprendizado oriundo das disciplinas didático-pedagógicas recorrentemente carece de experimentações e problematizações em contextos de prática.

Assim, embora alguns professores estejam predispostos a desenvolver uma prática que reproduza ou cultive suas crenças e valores, outros - e provavelmente em maior número - não percebem que, ensinar é um modo de conceber e estabelecer relação com o mundo e com Matemática. Ou seja, há um currículo oculto subjacente à ação pedagógica desse professor, pois ele ensina muito mais do que pensa estar ensinando. O futuro professor não aprende dele apenas uma Matemática, internaliza também um modo de concebê-la e de tratá-la e avaliar sua aprendizagem. (FIORENTINI, 2005, p. 110-111).

Observa-se que, mesmo com a implementação de diferentes reformas nos cursos de formação de professores ao longo dos últimos 20 anos, ainda assim existe a necessidade de se pesquisar e se reformular as propostas de formação inicial desses profissionais. Com relação à formação de professores de Matemática a realidade não é diferente, diversos problemas, como, por exemplo, a articulação entre teoria e prática ou a incoerência entre planejamento curricular e vivência acadêmica, já foram detectados. Buscar identificar outros problemas ou encontrar caminhos, tem se mostrado uma estratégia para repensar os cursos de licenciatura.

Contudo, a partir do panorama apresentado, este artigo tem como objetivo investigar a (des)articulação entre os conhecimentos matemáticos e didáticos-pedagógicos a partir da percepção de professores em início da docência em matemática. Para tanto foram entrevistados seis egressos como será apresentado na próxima seção. 


\section{PRODUÇÃO DOS REGISTROS}

Para a produção dos registros foram entrevistados seis professores egressos do Curso de Licenciatura em Matemática da Universidade Federal do Rio Grande - FURG e optou-se por selecionar os egressos que vivenciaram uma experiência de formação pautada no atual PPC, por isso participaram dessa pesquisa um egresso formado em 2017/01 e cinco egressos formados em 2017/02, totalizando seis professores.

Os registros foram produzidos a partir de conversas com esses professores balizadas em um roteiro de entrevista (Quadro 1) organizado em três eixos: Caracterização; Reflexões sobre a etapa de formação inicial; e Reflexões sobre a etapa pós-formação.

Quadro 1: Roteiro de entrevista

\section{Eixo 1 - Caracterização}

01. Qual a sua idade?

02. Sexo: ( ) M ( ) F ( ) PREFIRO NÃO RESPONDER.

03. Em que tipo de escola você cursou o ensino médio?

04. Em que ano você se graduou?

05. Em quantos anos você concluiu o curso? Foi seu primeiro curso de graduação?

06. Que motivos te trouxeram para o curso de licenciatura em Matemática?

07. Você foi bolsista durante a graduação ou recebeu algum tipo de auxílio ou em algum projeto de pesquisa/extensão/ensino/cultura durante a graduação? Se sim, qual? Se não, a quais motivos você atribui esse fato?

08. Você trabalhou durante algum período de sua graduação? Se sim, por quanto tempo? Descreva um pouco como era sua rotina.

09. Você trabalha atualmente? Em que área? Quantas horas por semana?

10. Você está fazendo ou pensa em fazer alguma pós-graduação relacionada a docência? Por quê?

\section{Eixo 2 - Reflexões sobre a etapa de formação inicial}

11. Você leu/conheceu o Projeto Pedagógico do Curso?

12. Durante a graduação, em algum momento, foi valorizado/considerado teu conhecimento prévio em Matemática? Se sim, de que forma?

13. Como você percebe a relação entre formação na área específica e formação para a docência durante sua formação inicial? Acreditas que a Instituição ofereceu uma prática integradora de conhecimentos destas duas áreas?

14. Você chegou a ter contato, durante sua formação, com a realidade escolar de nossa região? Em quais momentos?

15. Além do estágio Supervisionado, a Universidade te proporcionou algum outro contato com a experiência docente? Quais? Julgas que isso foi/seria importante para sua formação?

16. Como você avalia a relação entre teoria e prática durante o seu processo formativo?

17. Quais foram as experiências pedagógicas que mais te marcaram durante sua formação?

18. Quais conhecimentos você acredita ter se apropriado durante seu processo formativo? O que favoreceu isso? 


\section{Eixo 3 - Reflexões sobre a etapa pós-formação}

19. Quais foram suas principais dúvidas ao se formar? O curso te forneceu subsídios para sua continuidade?

20. Ao concluir o curso, como você se sentia em relação a exercer a docência?

21. Quais suas concepções hoje sobre os conhecimentos teóricos, relacionados à educação, estudados ao longo de sua graduação? E os relacionados à Matemática?

22. Que outras possibilidades profissionais de atuação você percebe para o licenciado em Matemática?

23. Que sugestões você faria para o curso?

Fonte: Os autores, 2018.

A partir do primeiro tópico de questões - "Caracterização" - tornou-se possível analisar algumas características inerentes ao grupo de entrevistados. Primeiramente observou-se que 100\% dos entrevistados cursaram Ensino Fundamental e Médio em escola pública. Além disso, aproximadamente $83,33 \%$ concluiu a licenciatura em menos de 5 anos.

É possível ressaltar que a maior parte dos entrevistados têm idade entre 25 e 36 anos e que nenhum entrevistado tem menos de 23 anos ou mais de 49 anos. Sendo que a média aritmética da idade foi 27,5 anos.

Outro ponto que pode a ser considerado é a questão do licenciando trabalhador, como é possível observar na Figura 1, o público egresso apresentou uma distribuição bastante diversificada em relação a este quesito. De fato, existem egressos que não trabalharam durante o período de graduação, ou trabalharam apenas de forma pontual, mas também existem aqueles que exerceram algum tipo de atividade profissional formalmente durante o período de graduação.

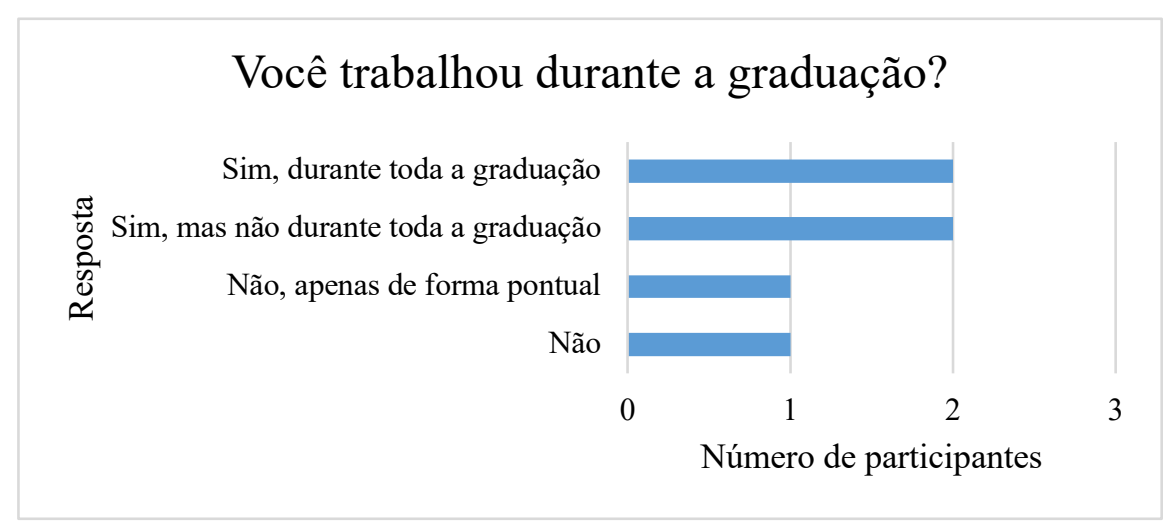

Figura 1: Trabalho e graduação.

Fonte: Os autores, 2018.

Sendo assim, percebe-se que os participantes deste estudo se caracterizam por um 
público bastante diversificado, indicando que a maioria que concluiu em menos de 5 anos a licenciatura, possui menos de 36 anos de idade e não trabalhou durante todo o período de graduação. Percebe-se também que, por se tratar de um curso noturno, pessoas das mais diferentes idades e realidades acabam por ingressar na licenciatura em Matemática, porém mesmo com toda essa variabilidade ainda assim é possível encontrar pontos em comum no discurso desses sujeitos. Na próxima seção, busca-se detalhar o processo de análise dos registros produzidos nesta pesquisa.

\section{DISCURSO DO SUJEITO COLETIVO COMO METODOLOGIA DE ANÁLISE}

Para analisar os relatos utilizou-se a técnica do Discurso do Sujeito Coletivo (DSC) proposta por Lefèvre e Lefèvre (2005) por se tratar de uma metodologia que torna possível explorar aspectos inerentes ao público egresso como um todo e não apenas peculiaridades presentes na trajetória individual de cada egresso.

O DSC consiste, então, numa forma não-matemática nem metalinguística de representar (e de produzir), de modo rigoroso, o pensamento de uma coletividade, o que se faz mediante uma série de operações sobre os depoimentos, que culmina em discursos-síntese que reúnem respostas de diferentes indivíduos, com conteúdos discursivos de sentido semelhante. (LEFÈVRE; LEFÈVRE, 2005, p. 25).

No DSC busca-se identificar e evidenciar percepções que estão presentes no coletivo de um grupo. Para tanto, se faz uso de três operações que Lefèvre e Lefèvre (2005) definiu como Expressões-Chave (ECH), Ideias Centrais (IC) e Ancoragens (AC). Segundo esse autor as ECH são pedaços, trechos do discurso, que devem ser destacados pelo pesquisador, e que revelam a essência do conteúdo do discurso ou a teoria subjacente. A IC é um nome ou expressão linguística que revela, descreve e nomeia, da maneira mais sintética e precisa possível, o(s) sentido(s) presente(s) em cada uma das respostas analisadas e de cada conjunto homogêneo de $\mathrm{ECH}$, que vai dar nascimento, posteriormente, ao DSC. Já as AC são afirmações genéricas usadas pelos depoentes para "enquadrar" situações particulares. Para que haja uma AC no depoimento é preciso encontrar, no corpo do depoimento, marcas discursivas explícitas dela. Entretanto, nesta pesquisa, optou-se por chamar de AC certas expressões linguísticas que conseguem, devido a sua abrangência, agrupar diversas IC em um mesmo conjunto. O Quadro 2 mostra um recorte do instrumento de análise dos discursos. 
Quadro 2: Instrumento de análise dos discursos

\begin{tabular}{|l|}
\hline \multicolumn{1}{|c|}{ Expressões-chave } \\
\hline EXT. 1: Eu acho que o curso, mesmo ele sendo de \\
licenciatura, busca muito mais o ensino da matemática \\
em si do que a preparação para a docência. Eu vi muito \\
poucas disciplinas trabalharem a docência em si. A não \\
ser os estágios, mas o que tu vais aplicar nos estágios é \\
diferente do que tu viu em sala de aula. A gente vê uma \\
matemática muito mais apurada, uma matemática de \\
ensino superior, e depois tu vais lá dar aula de ensino \\
fundamental, ensino médio. E até aquela preparação de \\
como te portar em sala de aula, como tu escreve no \\
quadro, o que existe em uma escola, o que tu vai \\
trabalhar, folha de chamada, percepção dos alunos. Isso \\
eu não vi na licenciatura.
\end{tabular}

EXT. 2: Como futuro professor de matemática, fazer a matemática conversar com a área de educação seria interessante para mim como futuro professor de matemática e ver isso acontecendo dentro do curso que eu me formo seria uma coisa interessante, então eu teria mais uma vivência. Então por isso eu acho que é importante.

EXT. 3: E talvez, porque tem muitas disciplinas da Matemática licenciatura que não servem para nada em se tratando da formação. Porque a gente é formado para a educação básica. São conteúdos que eu nunca vou lecionar para os meus alunos e que eu não vejo como eles servem de base para mim. Teve algumas disciplinas que eu senti isso.

EXT. 4: é claro que as professoras do estágio também estão lá para tirar dúvidas conceituais, não são só a respeito da aula ou do andamento da aula em si, mas é uma coisa que teoricamente, ao meu ver, o aluno já deveria chegar no estágio sabendo, porque é uma coisa conceitual, deveria ser revisto e repensado como vai ser ensinado para o aluno e muitas vezes não é o que acontece. Muitas vezes o aluno chega para tirar a dúvida do conceito com o professor do estágio.

EXT. 5: Com certeza, o PIBID principalmente porque na licenciatura só vai entrar dentro da sala de aula depois de um certo caminho. Depois que a gente já está no terceiro ano de curso é que a gente vai ter o contato com a sala de aula e o pibid me proporcionou isso antes.Quando eu fui para dar aula eu já tinha uma bagagem, já tinha todo um preparo para lidar com aquilo. Muita gente não tem essa oportunidade. Então o PIBID me ajudou bastante.

EXT. 6: Então são certas disciplinas que estão na ementa, que eu acho que é diferente a abordagem, é

\section{Ideias Centrais}

Desarticulação

conhecimentos matemáticos/ didático -pedagógicos

Divergência Escola/Universidade

Escola e Universidade

\section{Aproximação entre os eixos}

Necessidades conceituais emergentes na escola

Escola e Universidade

Conhecimentos

Matemáticos e

Conhecimentos didático-pedagógicos

Importância de outros

PIBID contatos com a docência 
uma abordagem mais avançada sim, mas se nesse meio do caminho eles abordassem questões que auxiliassem depois quando tu for dar aula eu acho que seria muito mais produtivo para quem quer ser professor do que reproduzir um livro.

Fonte: Os autores, 2018.

Os discursos são construídos a partir do agrupamento das ECH contidas na mesma $\mathrm{AC}$ de forma coerente e coesa. Para tanto, organizou-se as ECH em um editor de texto e selecionou-se entre essas ECH as que melhor representavam as diferentes IC. Posteriormente agrupou-se essas ECH representativas em um único parágrafo.

Para dar fluidez ao texto, foram acrescentados conectivos, que apresentam-se sublinhados, e suprimidas expressões que não alterariam a mensagem da $\mathrm{ECH}$, processos esses que são permitidos na técnica de construção do DSC (LEFÈVRE; LEFÈVRE, 2005).

Do processo de análise dos registros foram elaborados três discursos coletivos, como mostra a Figura 2:

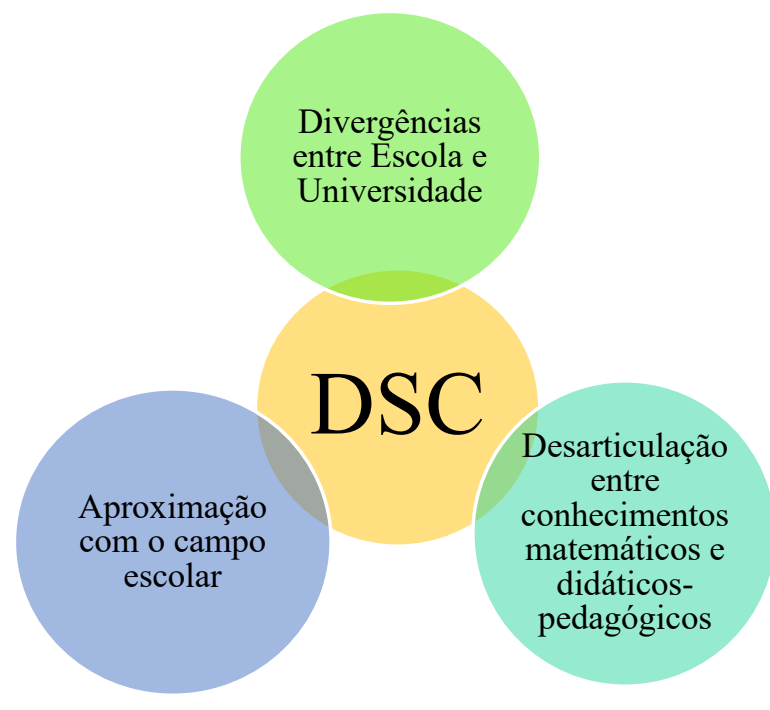

Figura 2: Discursos do Sujeito Coletivo construídos Fonte: Os autores, 2020.

A seguir, o discurso intitulado "Desarticulação entre conhecimentos matemáticos e didáticos-pedagógicos" será analisado juntamente com autores que corroborem com o tema dessa pesquisa. 
Lombardi, R. S.; Pereira, F. D.; Ayres, L. M. S. S.; Novello, T. P.

\section{DESARTICULAÇÃO ENTRE CONHECIMENTOS MATEMÁTICOS E DIDÁTICOS-PEDAGÓGICOS}

Para a construção desse DSC foram agrupadas as IC com relação a ideia de distanciamento entre o estudo dos conhecimentos matemáticos e o estudo dos conhecimentos didático-pedagógicos necessários à prática docente durante o processo de formação inicial. Através da aproximação dessas IC foi construído o discurso observado no Quadro 3 que evidencia um possível ponto de fragilidade de alguns cursos de licenciaturas em Matemática.

Quadro 3: Discurso do Sujeito Coletivo - Desarticulação entre conhecimentos matemáticos e didáticospedagógicos

O que marca bastante dentro do curso de matemática é justamente esse afastamento entre o eixo da educação e o eixo das disciplinas específicas. Isso é um discurso comum entre os alunos do curso e é uma coisa que marca a gente. Dentro do curso tem um modelo de trabalhar bastante diferente na parte do eixo da educação e no eixo de matemática. São modelos diferentes de aulas, de métodos de avaliação, de pedagogia, de metodologia para o trabalho. E eles, pelo menos para mim, não conversaram dentro do curso. Eu vejo muito que a matemática é aqui e a educação é aqui. As disciplinas da área da educação são bem distintas da área da matemática, mas são importantes também. É uma teoria diferente que acaba nos ajudando na aplicação da aula. Eu acho apenas que foi muito pouca a conversa entre os eixos. Por exemplo, tu aprende certos tópicos de filosofía, de sociologia aplicadas à educação, aplicadas à pessoas, mas fazer o paralelo com a educação matemática fica muito a cargo do aluno, porque não tem muito essa conexão. Muito poucas disciplinas conseguiram linkar uma coisa com a outra. Nesse sentido, o fato desses eixos conversarem poderia potencializar meu aprendizado, minha formação como professor. E como isso pode ser feito? de repente fosse uma pergunta que eu, depois de estar quase formado, devesse saber responder ou pelo menos dar um caminho, mas é difícil apontar uma ideia. Portanto, o curso, mesmo sendo de licenciatura, busca muito mais o ensino da matemática em si do que a preparação para a docência. Eu vi muito poucas disciplinas trabalharem a docência em si. A maioria dos professores ainda estão muito agarrados ainda àquela política antiga. $\mathrm{O}$ que era educação era educação, o que era específico era específico. Porém, fazer a matemática conversar com a área de educação seria interessante para mim como futuro professor de matemática e ver isso acontecendo dentro do curso que eu me formo seria uma coisa interessante, eu teria mais uma vivência.

Fonte: Os autores, 2020.

A ideia de desarticulação entre os conhecimentos matemáticos e didáticopedagógicos durante o processo de formação inicial surge recorrentemente em todo o DSC. Contudo, nota-se que a cada novo momento são acrescentados outros pontos de reflexão que acabam por complementar o sentido desse discurso. Ao dizer que "o que marca bastante dentro do curso de matemática é justamente esse afastamento entre o eixo da educação e o eixo das disciplinas específicas. Isso é um discurso comum entre os alunos do curso e é uma coisa que marca a gente" (DSC) o egresso expressa claramente o quão presente está na percepção dos licenciandos do curso de Matemática esse sentimento de 
desarticulação. Por isso, o que se percebe ainda hoje é uma resistência velada, por parte de alguns docentes, em romper esse distanciamento e falta de articulação. Tal fato evidenciase ao longo de todo DSC, por exemplo, quando o egresso diz:

Dentro do curso tem um modelo de trabalhar bastante diferente na parte do eixo da educação e no eixo de matemática. São modelos diferentes de aulas, de métodos de avaliação, de pedagogia, de metodologia para o trabalho. E eles, pelo menos para mim, não conversaram dentro do curso. (DSC)

Considerando o extrato acima é possível verificar que o egresso percebe no curso de licenciatura em Matemática a existência de uma nítida separação entre os docentes que são matemáticos e os que são educadores matemáticos. Segundo Fiorentini e Lorenzato (2006) os matemáticos normalmente buscam uma educação para a Matemática, compreendendo esta como um fim em si mesma e favorecendo uma formação muito mais voltada à pesquisa do que ao ensino. Já os educadores matemáticos buscam uma educação pela Matemática, ou seja, buscam através dela favorecer a formação intelectual do estudante, a Matemática deixa de ser um fim e passa a ser um meio, um instrumento que está a serviço da educação.

Observando ainda o exposto no DSC percebe-se que não somente a falta de referencial educacional nas disciplinas voltadas ao estudo de conhecimentos matemáticos pode comprometer à formação docente, mas também a falta de articulação entre o estudo dos conhecimentos pedagógicos e o estudo dos conhecimentos matemáticos nas disciplinas didático-pedagógicas, pode acarretar uma carência formativa ao futuro professor de Matemática. Nesse sentido, Fiorentini (2005) atenta que não somente a reprodução da tradição pedagógica pode comprometer à formação docente, mas também que disciplinas didático-pedagógicas com excesso de prescrições para o professor ou com excesso de críticas às práticas vigentes sem conseguir contrapor uma experiência diversa da criticada pode acarretar uma desvalorização dos conhecimentos abordados nessas disciplinas e, consequentemente, também comprometer a formação docente.

Ademais, ao dizer que "eu vejo muito que a matemática é aqui e a educação é aqui. As disciplinas da área da educação são bem distintas da área da matemática, mas são importantes também" (DSC) o egresso novamente destaca o distanciamento entre os conhecimentos matemáticos e didático-pedagógicos, porém, ressalta agora a importância de ambos os estudos para sua formação inicial. Voigt (2012) aponta no mesmo sentido ao 
evidenciar que para os egressos analisados em sua pesquisa ambos os conhecimentos matemáticos e didático-pedagógicos - são também considerados aspectos importantes para a formação voltada à prática de sala de aula. Isso pode ser um indício de que o curso de licenciatura analisado nesta pesquisa tem trilhado um caminho minimamente coerente no que tange às abordagens didático-pedagógicas, já que estas não têm sido consideradas apenas acessórios teóricos sem implicação prática, mas sim aspectos relevantes à docência. $\mathrm{Na}$ continuação do DSC o egresso evidencia o viés prático desses conhecimentos, mas acrescenta um outro ponto de crítica.

É uma teoria diferente que acaba nos ajudando na aplicação da aula. Eu acho apenas que foi muito pouca a conversa entre os eixos. Por exemplo, tu aprende certos tópicos de filosofia, de sociologia aplicadas à educação, aplicadas à pessoas, mas fazer o paralelo com a educação matemática fica muito a cargo do aluno, porque não tem muito essa conexão. Muito poucas disciplinas conseguiram linkar uma coisa com a outra. (DSC)

Nesse ponto o egresso atenta para o fato de algumas disciplinas do "Núcleo Comum das Licenciaturas", que "visam promover uma sólida formação pedagógica para a prática docente" (PPC, 2011, p. 8), não terem conseguido estabelecer, na prática, uma relação com o ensino de Matemática. Nessas disciplinas normalmente são agrupados alunos de diferentes licenciaturas, o que, em tese, poderia tornar a sala de aula um ambiente extremamente propício a propostas voltadas para questões interdisciplinares. Porém, é claro que não se pode exigir que o docente responsável pela disciplina tenha um domínio conceitual amplo o suficiente para relacionar, sozinho, a ementa de sua disciplina com as mais diferentes áreas de estudo de seus alunos. Nesse sentido, o que parece estar sendo questionado pelo egresso é, então, a falta de atividades dentro dessas disciplinas que visem a construção de significado por parte dos licenciandos.

Para Fino (2001), em uma sala de aula é possível considerar que cada aluno possui a sua "janela de aprendizagem". Isso sugere que, dentre outros pontos, ao se fornecer os recursos adequados, podendo ser a simples mediação do professor ou o trabalho em equipe com seus pares, os alunos podem superar barreiras que dificilmente superariam individualmente. Sendo assim, percebe-se a importância dos docentes da formação inicial propiciarem, em suas aulas, atividades que potencializem a reflexão e a aproximação entre os estudos teóricos e a atividade docente.

O discurso é complementado ao dizer que "o fato desses eixos conversarem poderia potencializar meu aprendizado, minha formação como professor"' (DSC). De fato, nessa 
fala percebe-se o distanciamento entre os eixos - matemático e didático-pedagógico - como uma fragilidade no processo de formação inicial e que aproximá-los tornou-se uma das necessidades da licenciatura em Matemática. Entretanto, o futuro professor nem sempre consegue apontar caminhos para romper com essa visão dicotômica. Ao se questionar sobre como encarar esse problema o egresso reflete: "E como isso pode ser feito? de repente fosse uma pergunta que eu, depois de estar quase formado, devesse saber responder ou pelo menos dar um caminho, mas é dificil apontar uma ideia” (DSC). Observa-se assim que, talvez por não vivenciar uma experiência integradora de conhecimentos durante o processo de formação inicial, o egresso venha a carregar consigo uma certa insegurança quanto à forma de articular os conhecimentos concretizados durante sua formação inicial, fato esse que poderá refletir em sua prática de sala de aula.

Fiorentini e Lorenzato (2013), ao analisar pesquisas que abordam a formação do professor de Matemática, apontam a existência ainda de uma quase tricotomia entre a formação Matemática, a formação didático-pedagógica e a prática profissional. A formação Matemática está mais voltada ao estudo acadêmico da Matemática, sem necessariamente estabelecer relações com o contexto escolar ou com a perspectiva didático-pedagógica. Já a formação didático-pedagógica ainda está distante da Matemática acadêmica e do contexto real de sala de aula. Por fim, nessa visão, os conflitos e a realidade da prática profissional nem sempre estão presentes nos currículos dos cursos de licenciatura.

Cabe ressaltar que o cenário formativo da licenciatura em Matemática analisada nesta pesquisa apresenta relação com essa visão quase tricotômica da formação docente. Na continuação do DSC o egresso evidencia isso ao dizer:

o curso, mesmo sendo de licenciatura, busca muito mais o ensino da matemática
em si do que a preparação para a docência. Eu vi muito poucas disciplinas
trabalharem a docência em si. A maioria dos professores ainda estão muito
agarrados ainda àquela política antiga. O que era educação era educação, o
que era específico era específico. Porém, fazer a matemática conversar com a
área de educação seria interessante para mim como futuro professor de
matemática e ver isso acontecendo dentro do curso que eu me formo seria uma
coisa interessante, eu teria mais uma vivência. (DSC)

Ao acreditar em uma experiência formativa que relacione os conhecimentos matemáticos aos conhecimentos didático-pedagógicos e ao contexto escolar ao qual irá atuar o futuro professor de Matemática não está sendo dito que este deva aprender menos Matemática, mas sim que a abordagem e a exploração dos conteúdos sejam diferenciadas, 
como por exemplo, das de um bacharel em Matemática. Fiorentini e Lorenzato (2013, p. 231) não apontam para uma desvalorização ou uma redução do conhecimento matemático estudado durante o processo de formação inicial do professor de Matemática, mas sim para que se reconheça a necessidade desse professor desenvolver "um repertório de estratégias e recursos vinculados ao processo de construção escolar do saber matemático". Esse autor reflete também sobre os benefícios à formação docente quando o licenciando vivencia o processo de exploração e investigação nas disciplinas voltadas ao estudo acadêmico da Matemática. Assim,

não se trata, portanto, de apenas mudar ementas ou reestruturar grades curriculares. São importantes os conteúdos da matemática superior que compõem as disciplinas de formação matemática da licenciatura, pois amplia-se, assim, a visão dos futuros professores acerca da matemática como campo de conhecimento. Mas, é necessário adotarmos posturas que apontem para uma visão mais integradora do curso, sem deixar de aprofundar, numa perspectiva multirrelacional, epistemológica e histórico-cultural, o conteúdo específico. (FIORENTINI, 2013, p. 935)

Embora o atual PPC preveja como competências e habilidades para o licenciando as capacidades de "trabalhar na interface da Matemática com outros campos do saber" (PPC, 2011, p. 6) e “estabelecer relações entre a Matemática e outras áreas do conhecimento" (PPC, 2011, p. 6) além de pretender que "as disciplinas deixem de ser vistas isoladamente e passem a serem instantes de um conhecimento agregado" (PPC, 2011, p. 7). $\mathrm{Na}$ análise deste documento não foram encontrados mecanismos que efetivamente fomentem ou propiciem tais vivências dentro do curso, assim a essas articulações ficam muito na vontade do professor.

Assim, percebe-se que a desarticulação entre conhecimentos matemáticos e didático-pedagógicos ainda está muito presente no curso de licenciatura em Matemática da FURG e é evidenciada pelos egressos como um fator limitante da formação docente. Cabe, pois, refletir em estratégias a serem contempladas no curso para superar tal fragilidade, e formalizar tais estratégias no PPC do curso, uma vez que independeria, assim, do professor que ministrasse tais disciplinas.

\section{CONSIDERAÇÕES FINAIS}

Ao longo das últimas décadas inúmeras foram as pesquisas que buscaram compreender o processo de constituição docente. Alguns estudos apontaram para os saberes envolvidos na construção da identidade docente, outros evidenciaram acertos e 
contradições nos processos de formação. Porém, independentemente do avanço e aprofundamento teórico nesse campo do saber, o que se percebe é que os cursos de formação de professores ainda apresentam fragilidades e desafios a serem superados. Em meio a esse cenário, esta pesquisa buscou investigar, por meio do discurso dos egressos, qual a relação entre o cenário formativo idealizado no atual PPC do curso de Licenciatura em Matemática da FURG e o efetivo processo formativo desse curso.

O conversar com os autores que balizaram esse estudo, permitiu expandir e aprofundar as interpretações inicialmente suscitadas. Salienta-se ainda, que a metodologia de pesquisa escolhida para produção dos registros e a técnica de análise utilizada se mostrou adequada aos objetivos do estudo e permitiu uma compreensão mais ampla do atual contexto formativo da licenciatura investigada. Devido a limitação temporal que existe em um TCC alguns aspectos da formação docente não puderam ser abordados nesta pesquisa. Assim, na etapa de análise dos discursos foram exploradas algumas fragilidades e potencialidades da atual organização acadêmica que foi evidenciado na fala dos egressos entrevistados.

Ao analisar o DSC foi possível perceber que alcançar uma formação docente mais completa, não basta apenas aproximar a Matemática acadêmica da Matemática escolar, também é preciso integrar o estudo dos conhecimentos didático-pedagógicos com o estudo dos conhecimentos matemáticos. Essa integração deve se dar tanto nas disciplinas voltadas ao estudo dos conhecimentos matemáticos quanto nas disciplinas didático-pedagógicas.

Entretanto, não está sendo solicitado que se estude uma Matemática mais simplificada ou que se abandone os estudos de teóricos da área de educação. O que está sendo apontado é que o estudo avançado da Matemática busque, talvez através de uma mudança metodológica, suscitar construções mentais que enriqueçam o saber docente e não apenas capacitem o futuro professor a trabalhar com somente conceitos matemáticos.

Caminhos que rompem com a visão rígida da Matemática, abordando sua epistemologia e seu viés histórico-social, seus processos de construção e re-construção, tem se mostrado alternativas para buscar essa integração de conhecimentos. Além disso, também está sendo solicitado que as disciplinas voltadas ao estudo didático-pedagógico, além de fornecer subsídios teóricos para a prática do futuro docente, busquem também adentrar em contextos de prática para que assim o licenciando possa realmente experienciar aquilo que estuda. 


\section{REFERÊNCIAS}

BRASIL. Ministério da Educação. Conselho Nacional de Educação. Parecer CNE/CP 1, 18 de fevereiro de 2002 - Institui Diretrizes Curriculares Nacionais para a Formação de Professores da Educação Básica, em nível superior, curso de licenciatura, de graduação plena. (2002a). Brasília: Diário Oficial da União, 9 abr. 2002, Seção 1, p. 31. Disponível em: <http://portal.mec.gov.br/cne/arquivos/pdf/rcp01_02.pdf>. Acesso em: 12 nov. 2017.

FINO, C.M.N. Vygotsky e a Zona de Desenvolvimento Proximal (ZDP): três implicações pedagógicas. Revista Portuguesa de educação, v. 14, p. 273-291, 2001.

FIORENTINI, D. A formação Matemática e didático-pedagógica nas disciplinas da licenciatura em matemática. Revista de Educação PUC-Campinas, n. 18, p. 107-115, 2005.

FIORENTINI, D; LORENZATO, S. Investigação em educação matemática: percursos teóricos e metodológicos. 2. ed. rev. Campinas: Autores Associados, 2006.

FIORENTINI, D; OLIVEIRA, A. T. C. C. O Lugar das Matemáticas na Licenciatura em Matemática: que matemáticas e que práticas formativas?. Boletim de Educação Matemática, v. 27, n. 47, 2013.

GATTI, B.A. Formação de professores no Brasil: características e problemas. Educação \& Sociedade, v. 31, n. 113, 2010.

LEAL, M. F. C. Teoria e Prática no Processo de Formação Profissional: O Caso de um Curso de Licenciatura em Matemática. 2016. 235 f. Tese (Doutorado em Educação Matemática) - PUC-SP, São Paulo, 2016.

LEFÈVRE, F.; LEFĖVRE, A. M. Discurso do Sujeito Coletivo: um novo enfoque em pesquisa qualiquantitativa (Desdobramentos). 2. ed. Caxias do Sul, RS: Educs, 2005. 256 p. (Coleção Diálogos).

UNIVERSIDADE FEDERAL DO RIO GRANDE - FURG. Projeto PolíticoPedagógico do Curso de Licenciatura em Matemática - Rio Grande do Sul. 2011. Disponível em:

$<$ http://www.imef.furg.br/images/stories/documentos/projeto_pedaggico_matemtica_lice nciatura.pdf $>$. Acesso em 5 Nov. 2017

VOIGT, J. M. R. Sentidos e Significados de Egressos da Licenciatura em Matemática à sua Formação Inicial. 2012. 174 f. Tese (Doutorado em Educação: Psicologia da Educação) - PUC-SP, São Paulo, 2012. 